\title{
Relações interétnicas, processos de construção da identidade e estratégias etnopolíticas mapuches no Departamento Los Lagos, Neuquén, Argentina
}

\author{
L Sebastián Valverde e Analía García
}

\begin{abstract}
resumo Este trabalho analisa o processo de construção da identidade étnica em famílias de origem mapuche de Villa La Angostura (Departamento de Bagos), na província de Neuquén, de acordo com as políticas levadas a cabo pelo Estado Nacional e Provincial. Como hipótese de trabalho propomos diferentes conjunturas nacionais a partir das quais, no decorrer do século XX, a identidade "étnica" foi prejudicando a situação destes grupos domésticos em relação ao acesso à terra. Para tanto, analisamos a função das instituiçốes estatais encarregadas de regular o acesso a ela. Posteriormente, perguntamo-nos acerca do processo de mobilização social surgido a partir de 2003 , focalizando o contexto econômico que abrange a cidade. Nesse ponto, analisamos diversas políticas estatais que tendem a promover este tipo de reivindicação e verificamos a incidência destas na visibilidade do protesto e revalorização da identidade mapuche.
\end{abstract}

palavras-chave Indígenas. Estado. Identidade.

\section{Introducción}

Villa la Angostura está ubicada en la cabecera del Departamento "Los Lagos" de la provincia de Neuquén, Argentina. Situada en la Patagonia, sobre la Cordillera de los Andes, queda a $42 \mathrm{~km}$ del paso fronterizo "Cardenal Antonio Samuré" hacia Chile. Se asienta sobre la orilla norte del Lago Nahuel Huapi y se extiende hasta el Lago Correntoso en una zona de grandes bellezas naturales. Se encuentra a $473 \mathrm{Km}$ de la capital neuquina, a $80 \mathrm{Km}$ de San Carlos de Bariloche (Provincia de Río Negro) y a 110 Km de San Martín de los Andes (por el circuito turístico de "Los Siete Lagos"). Toma el nombre del istmo que une tierra firme y la península de Quetrihué, produciendo un estrechamiento llamado "angostura" (Municipalidad de Villa la Angostura, 2006).

Villa la Angostura se fundó oficialmente en mayo de 1932 (cuando se inauguró el edificio de la oficina radiotelegráfica "Correntoso"), si bien su desarrollo fue lento durante la primera mitad del siglo XX, permaneciendo aislada de los centros urbanos regionales por la falta de vías de comunicación. De hecho, al comienzo de la década de los 90 se pavimentó la ruta 231 que comunica a la localidad con Bariloche. La conexión con San Martín de los Andes es por camino de tierra (el ya mencionado camino de "Los Siete Lagos") que suele cortarse en la temporada invernal por las nevadas. En estos casos la villa depende casi con exclusividad de Bariloche para las comunicaciones y el arribo de turistas.

Con el asfaltado de la ruta 231, en 1994, comenzó, entonces, a intensificarse el crecimiento de la localidad. Su acelerado incremento poblacional continúa hasta nuestros días: entre 1991 y 2001, Villa la Angostura pasó de 3.056 habitantes a 7.325 (INDEC, 2001); para 2006 se estima una población de 11.285 habitantes (Subsecretaría de turismo, 2006).

Sus actividades económicas se concentran principalmente en el turismo y la construcción, manteniéndose desde su fundación como una opción para visitantes de alto poder adquisitivo. De hecho, cuenta con estancias y 
I 4 | Sebastián Valverde e Analía García

residencias de reconocidas familias de la aristocracia argentina.

Las actuales condiciones económicas a nivel nacional, favorables al turismo extranjero, han acentuado la imagen de esta aldea de montaña, caracterizada por un paisaje agreste rodeado de las montañas de la Cordillera de los Andes y los lagos del sur. Históricamente, ha sido el lugar de descanso de la Patagonia privilegiado por la clase alta terrateniente de la provincia de Buenos Aires. Así que, desde entonces hasta nuestros días, es el lugar elegido de la Patagonia argentina para un turismo de élite.

Si bien las ciudades próximas cuentan con la presencia de comunidades mapuche reconocidas jurídicamente en los aspectos económicos, políticos y culturales, en Villa La Angostura no existe tal reconocimiento de los derechos indígenas. No obstante, desde el año 2003, dos grupos de familias residentes en esta localidad y en parajes próximos, los Lof Paichil Antriao y los Lof Quintriqueo ${ }^{I}$, vienen realizando una serie de movilizaciones y reclamos judiciales en busca de su reconocimiento como pueblos originarios - un hecho inédito hasta el momento. Aunque el gobierno provincial no haya dado lugar al pedido, estas reivindicaciones han instalado un debate público en torno a la preexistencia indígena en una localidad que siempre se consideró "sin indígenas". Asimismo, estos reclamos han agudizado el enfrentamiento entre diversos niveles gubernamentales, ya que el Estado Nacional - a través de la Administración de Parques Nacionales y del Instituto Nacional de Asuntos Indígenas (INAI) - ha reconocido las demandas mapuche.

1. El pueblo mapuche (gente de la tierra) reside en la actualidad en áreas rurales y urbanas de las provincias de Buenos Aires, La Pampa, Neuquén, Río Negro y Chubut. La Encuesta Complementaria de Pueblos Indígenas (ECPI) indica que el pueblo mapuche es el más numeroso de la Argentina con algo más de 100.000 integrantes (INDEC, 2006).
De este modo, diferentes objetivos guían el presente artículo. Por un lado, nos interesa reconstruir el proceso histórico de constitución de Villa La Angostura para comprender la invisibilización de la presencia indígena en la ciudad y alrededores, con el consiguiente proceso de des-adscripción étnica que ha prevalecido desde fines del siglo XIX. En relación a este punto, prestamos particular atención al poder político y económico desempeñado por el Estado Nacional argentino a través del órgano que ejerció autoridad en la zona - la Administración de Parques Nacionales - y a la ausencia relativa del Estado Provincial neuquino en la localidad.

Por otro lado, daremos cuenta del reciente proceso de re-adscripción étnica protagonizado por poblaciones mapuche y de la agudización de conflictos que esto supone en un contexto de creciente explotación turística, concentrándonos en aquellos litigios asociados con disputas territoriales. En este punto adquiere relevancia el análisis de las estrategias etnopolíticas desplegadas por las familias indígenas, lo que resulta fundamental para comprender la creciente visibilización pública de estas familias, con el consiguiente debate instalado en la localidad acerca de la movilización étnica.

En este sentido, nuestra hipótesis de trabajo sostiene que los procesos de adscripción y des-adscripción étnica se encuentran condicionados por la institucionalidad política y por las contradicciones entre diferentes niveles estatales que viabilizan u obstaculizan la identidad basada en este tipo de pertenencia.

Para situar la problemática que involucra hoy a la población mapuche de esta zona, entendemos que tal como plantean algunos investigadores, la categoría de "relaciones interétnicas" tiene dos connotaciones diferentes (Bechis, 1992; Trinchero, 2000). Por un lado, aquella que alude a la interacción entre distintas unidades o "grupos étnicos" en el sentido sugerido por Barth. Por otro lado a la interacción 
entre etnias diferentes dentro de un sistema social determinado.

Con relación al primer tipo de abordajes, el gran impacto de la obra de Fredrik Barth (1976 [1969]) sobre los grupos étnicos y sus fronteras impuso una apertura hacia nuevas miradas. Sus conceptos significaron una ruptura respecto a los abordajes "culturalistas" de los años 1940 y 1950. Aquellas perspectivas, propensas a crear límites artificiales entre los pueblos sin organizaciones estatales, definían "lo indígena" sobre la base de rasgos culturales "estáticos" e identificaban "una raza con una cultura" (Hidalgo, 1992). Por el contrario, Barth va a hacer hincapié:

(...) en el hecho que los grupos étnicos son categorías de adscripción e identificación que son utilizadas por los actores mismos y tienen la característica de organizar la interacción entre los individuos (1976, pp. 10 - 11).

De esta forma, se desvía el foco de la investigación desde la historia de los grupos y su constitución interna, hacia los límites étnicos y su persistencia.

No obstante, si bien el planteo de Barth logra trascender el análisis de los grupos étnicos en base a sus supuestas "esencias" de rasgos culturales, diferentes autores han señalado las limitaciones que presenta este abordaje para el análisis de las complejas dinámicas étnicas.

Los investigadores que conforman la segunda aproximación que hemos señalado, han analizado las interacciones entre grupos étnicos en el marco de un sistema social determinado (Cardoso de Oliveira, 1992; Bartolomé, 1997; Diaz Polanco, 1995; Bechis, 1992; Trinchero, 2000; Vazques; 2004; Belli \& Salutsky, 2003; Radovich, 1992). Dentro de estas propuestas Cardoso de Oliveira (1992) destaca:

(...) en primer lugar que las relaciones interétnicas solo se pueden comprender de una manera fructífera si se las inserta en un sistema social de carácter interétnico que las condiciona, determinando su propia estructura y desarrollo; en segundo lugar, que ese sistema interétnico, constituido por procesos de articulación étnica, no puede dejar de referirse a procesos de articulación social de otro tipo, como los que relacionan a otros sectores de la sociedad global, ya sean los interregionales, los interclase, o aún aquellos que vinculan a los sectores rural y urbano (Cardoso de Oliveira, 1992, p. 61).

Recuperando los aportes de estos autores, nuestro abordaje de la cuestión étnica se diferencia tanto de las concepciones "esencialistas", como de las aproximaciones interaccionistas de Barth. De esta forma, nos proponemos visualizar las relaciones interétnicas desde las interrelaciones que se establecen entre los diferentes grupos, pero considerando su inserción en un contexto social más amplio. Esto contempla las condiciones históricas y estructurales que configuran a los diversos grupos, y a las relaciones dinámicas - contradictorias y conflictivas - que se establecen entre los mismos.

\section{El proceso de des-adscripción étnica durante el siglo XX (primera parte): indígenas y chilenos en el Nahuel Huapi}

La historia oficial de Villa la Angostura se remonta al año 1902, cuando el Gobierno Nacional liderado por Julio A. Roca creó la Colonia Pastoril Agricola Ganadera Nahuel Huapi, con el fin de fomentar el principal objetivo buscado en todo aquel territorio dado a los indígenas y disputado a los chilenos: el afianzamiento de la soberanía nacional a partir de la creación de asentamientos poblacionales. Esta Colonia ocupaba una parte del Territorio Nacional de Neuquén (que corresponde al actual Departamento de Los Lagos) y 
un sector del Territorio Nacional de Río Negro (hoy Departamento de Bariloche). La Colonia Pastoril estaba integrada - entre otros - por los lotes 9 y 10 donde posteriormente, hacia 1930, se consolidó el centro de Villa La Angostura (De Mendieta, 2002).

En esta zona, la circulación de población entre la frontera argentino-chilena ha sido más intensa que en otras áreas, en tanto el espacio económico y social de la región no se ajustaba a los límites territoriales de los Estado-Nación. De tal modo que las vinculaciones con el país trasandino incidieron fuertemente en la configuración local (Favaro, 1993). Tras la "Campaña al Desierto" (avanzada militar efectuada a fines del Siglo XIX sobre las poblaciones indígenas) contingentes de población chilena cruzaron la cordillera en dirección al Nahuel Huapi. Los motivos de esta migración fueron diversos: las dificultades en el acceso a la tierra para los sectores más pobres, además de la búsqueda de una mejor calidad de vida (Mendez, 2005). En este sentido, cabe resaltar que la Cordillera de los Andes se fija como frontera ante la conformación de los Estados Nacionales, tanto argentino como chileno, pero como frontera, no formaba parte del imaginario de las poblaciones cuyo circuito de intercambio socioeconómico trasvasa los límites impuestos en términos de soberanías nacionales. Por ello, poblaciones mapuche se encuentran tanto en la Patagonia chilena como en la argentina, manteniendo intensas relaciones intraétnicas hasta nuestros días.

Dada esta significativa presencia de población extranjera, el Estado consideró estratégico y prioritario afianzar la "identidad nacional", aplicando una política de "des-chilenización". Los informes de las Inspecciones de Tierras ponen de manifiesto que el prejuicio anti-chileno fue una constante en las primeras décadas del siglo XX. En 1912, un inspector de la Colonia Nahuel Huapi establecía una clara antinomia entre el extranjero europeo ("responsable", "capitalista" y "trabajador") y el chileno (catalogado como "vago" y "sin recursos"). Citamos sus expresiones referidas a los colonos: "(...) se componen de chilotes enviciados con muy poco amor al trabajo y al progreso" (Mendez, 2005, p. 3).

Expresiones similares se vertían sobre los indígenas que se instalaron en el Nahuel Huapi en los años siguientes a la "Conquista al Desierto", algunos corridos por la campaña de exterminio y otros provenientes del otro lado de la cordillera. Esta población era con frecuencia subsumida en la categoría de "chilenos", con el fin de redoblar el estigma que pesaba sobre las comunidades originarias locales. En 1903 un funcionario de la Colonia Agrícola Nahuel Huapi sostenía:

(...) los únicos que tienen verdaderamente condiciones para colonos son los alemanes pues tanto los indios como los chilotes se limitan a sembrar trigo y las papas que necesitan para su consumo empleándose después como peones a jornal. Es gente dañina y viciosa incapaz de un trabajo continuado que en cuanto tiene algunos fondos se entrega a la bebida y a toda clase de excesos hasta consumir el último centavo volviendo recién entonces a trabajar (Vallmitjana, 2002, p. 9).

Tanto indígenas y chilenos eran categorizados por fuera de lo que se consideraba recursos humanos necesarios para cumplir con el objetivo propuesto para las colonias agrícolapastoriles: convertir la tierra en capital productivo en el marco de un proyecto nacional. En otras palabras, estas colonias debían cumplir una función económica pero también geopolítica: hacer efectiva la ocupación del territorio, en paralelo al desarrollo de un sentimiento de "nacionalidad argentina". En este contexto, la adscripción étnica constituía un hecho desventajoso para tener acceso a la tierra.

Sin embargo, esto no impidió que la necesidad de hacer efectiva la ocupación de la tierra ocasionara que en 1902 (20 años después de la 
Conquista al desierto) el Presidente de la Nación Julio A. Roca concedió el lote 9 (actualmente Villa la Angostura) a Don Ignacio Antriau y a José María Paisil - jefes de sus respectivas familias-, quienes ofrecían el servicio de cruzar el río en bote a los viajeros que transitaban la senda que iba desde el Nahuel Huapi hasta el Paso Puyehue $^{2}$ (Vallmitjana, 1999, p. 8).

El decreto de 1902 que otorgaba el lote 9 a Paisil y Antriau señalaba, en su artículo No 2:

La división de tierras y colonias queda autorizada para exigir de los concesionarios de lotes, mencionados en el artículo primero de este decreto, justifiquen su ciudadanía argentina y demás condiciones prescriptas por la ley del $2 \mathrm{de}$ octubre de 1884 (Moreda, 2005).

La ciudadanía argentina era condición para usufructuar de las tierras, negándose cualquier otra identidad (étnica o nacional).

Como vemos, la entrega de tierras a los Paichil-Antriao no fue resultado de su adscripción étnica, sino que formó parte de la política de poblamiento y colonización implementada por el Estado nacional; así, ninguna de estas familias mapuche recibió títulos de tenencia precaria en virtud de su identidad originaria.

\section{El proceso de des-adscripción étnica durante el siglo XX (segunda parte): la política de Parques Nacionales y la ausencia relativa del Estado provincial}

El crecimiento de Villa la Angostura coincidió con la creación de la Administración de Parques Nacionales en la década de 1930. Desde el nacimiento de la entidad, ésta se transformó en el principal referente del Estado nacional sobre el territorio, ya que era responsable de su control

2. La forma de escribir los nombres cambia de un registro histórico a otro. y de la provisión de infraestructura básica (por ejemplo, de edificios públicos y privados). Esta agencia loteó tierras, asignó autorizaciones para la instalación de pobladores, fijó los cotos de caza y realizó el control de la tala de árboles.

Asimismo, la existencia de Parques Nacionales fue fundamental para la impronta simbólica otorgada a la zona, contribuyendo en la gestación de una imagen "alpina", concordante con el ideal estético y social que la clase dominante deseaba para el lugar, la aldea de montaña.

Una vez conformada la institución, la política respecto a las tierras que quedaron dentro de su jurisdicción fue dual: muy laxa cuando se trataba de ceder territorios a vecinos prestigiosos; sumamente estricta en el cumplimiento de la normativa vigente si los aspirantes eran personas de escasos recursos, más aún si eran chilenos e indígenas (Mendez, 2005, p. 5-8). Mientras cedía a los primeros títulos de propiedad, es decir derecho definitivo de acceso a la tierra; a los segundos, la Administración de Parques Nacionales entregó "Permisos Precarios de Ocupación”. Estos permisos no solamente no protegían de una eventual expulsión - el temido desalojo - sino que suponían una infinidad de trabas para sus ocupantes.

La institución fue funcional para la naciente clase dominante local, a los "pioneros" favorecidos con la propiedad de amplias extensiones de tierras. Prueba de este entrelazamiento de intereses fue el nombramiento de Ezequiel Bustillo en la dirección de la Administración de Parques Nacionales. Dueño de un latifundio en el Parque Nahuel Huapi, su mandato duró 10 años (De Mendieta, 2002). De esta forma, la política de Parques Nacionales favoreció la tendencia hacia la conformación de una fuerte élite local que hegemonizó los procesos de acumulación

3. Pioneros es una categoría nativa que pertenece al universo simbólico de los conquistadores patagónicos, aquellos que vinieron a poblar el desierto (por exclusión de la población autóctona). 
de capital, mientras la villa se encontraba aislada de los centros provinciales de poder.

En los registros catastrales de 1902 y 1903 , efectuados para la entrega de tierras, se registra la condición étnica de cada uno de los jefes de familia de la colonia agrícola-pastoril. En dichos listados, figuran los antepasados de las familias mapuche que en la actualidad ejercen el reclamo ante las autoridades nacionales y provinciales (Ellos se encuentran registrados como "indígena - botero", o "indígena - agricultor") y se sigue con la descripción de los bienes de capital poseídos por cada unidad doméstica, sobre todo se registra la cantidad de animales. Sin embargo, ya para 1934 y 1965, Parques Nacionales realizó dos censos de los ocupantes asentados sobre el Parque Nacional Nahuel Huapi. Varias cuestiones que deseamos señalar se desprenden de la lectura de estas fichas censales. Por un lado, no se menciona la pertenencia "indigena" de una parte importante de estos habitantes, muchos de los cuales son los antepasados de los pobladores que actualmente reclaman el reconocimiento de sus derechos ancestrales en la zona. Por otro lado, en estos documentos se dejó constancia de la expulsión de ocupantes con antecedentes policiales (Administración de parques nacionales, 1934). Estos documentos refuerzan nuestra hipótesis en cuanto a que la Administración de Parques Nacionales invisibilizó la adscripción étnica de los pobladores mapuche, en continuidad con las concepciones europeizantes (anti-chilenas y anti-indígenas) de las autoridades territorianas que ejercieron el poder desde fines del Siglo XIX y en las primeras décadas del siglo XX.

Por otro lado, las tierras concedidas a las familias Paichil-Antriao se fueron valorizando progresivamente a medida que se expandía Villa la Angostura; lo que llevó a diversos mecanismos por los cuales fueron gradualmente "corridos" hacia la marginalidad del lote 9. Los sistemas implementados fueron: cobro de impuestos por parte de Parques Nacionales, expulsión por antecedentes policiales o falta de documentos, venta de parcelas a valores bajos, endeudamiento fruto de relaciones de peonaje, sustracción de documentación probatoria de su residencia, sucesivas parcelaciones del lote original. Algunos interlocutores han hecho referencia a una suerte de anécdota local que tuvo lugar en los ańos 1940, cuando Segundo Paichil intercambió con un conocido vecino del lugar 40 hectáreas de tierras por "...una casilla y una caja de vicios por mes porque no tenía descendencia y estaba viejo para trabajar...".

Como resultado, fue creciendo el centro de Villa La Angostura, la municipalidad y los edificios públicos, el centro comercial y los barrios. Las familias mapuche quedaron confinadas en el límite norte del lote, en el camino que recorre el Cerro Belvedere.

Hacia 1964, el Estado Provincial lleva adelante el reconocimiento de reservas indígenas en territorios ocupados por familias mapuche $e^{4}$. Esta política provincial no se registró en Villa la Angostura ni en sus áreas circundantes, contribuyendo al gradual proceso de des-adscripción étnica. En síntesis, el desarrollo histórico local se caracterizó por la falta de reconocimiento de las poblaciones mapuches, principalmente como resultado del fuerte peso de las acciones desplegadas por Parques Nacionales. En relación a esta dinámica, Trinchero (2000) destaca que un factor clave en la construcción de las identidades indígenas constituyen las relaciones interétnicas establecidas durante el proceso

4. En el año 1964 durante la primera gestión del gobernador Felipe Sapag (1963-1966) fue dictado el decreto $0737 / 64$ y sus complementarios, a través de los cuales se concedía a un cierto número de comunidades indígenas el usufructo de la tierra que ocupaban. Por este motivo, al comenzar la década del 1970 existían en la provincia 23 comunidades, con tierras reconocidas y muchas otras asentadas de hecho o con "permisos precarios" (Falaschi, 1994, p. 6-13). 
de formación del Estado - Nación. De allí, la necesidad de

(...) inscribir las relaciones interétnicas al interior del proceso de formación de la nación y la estatalidad (y de las relaciones de producción que en el interior de sus fronteras se van desplegando) (Trinchero, 2000, p. 31).

\section{El "boom" turístico e inmobiliario de los últimos años}

Así como el proceso histórico que hemos analizado hasta aquí nos ha permitido contextualizar el predominio de la des-adscripción étnica entre la población indígena de Villa La Angostura; el actual "boom" turístico e inmobiliario de la localidad forma parte del contexto socioeconómico y político que favorece los recientes procesos de re-adscripción étnica ${ }^{5}$.

El crecimiento de la actividad turística en la villa se verifica a través de una serie de indicadores: el incremento del valor de la tierra para la construcción de complejos turísticos, el aumento en el nivel de ocupación de las plazas hoteleras, el surgimiento de comercios vinculados a la gastronomía, la creciente explotación del Cerro Bayo durante la temporada invernal. El incremento en la cantidad de plazas en alojamientos turísticos de esta localidad supera ampliamente a las restantes del sur neuquino, lo que evidencia su creciente importancia como centro turístico dentro del "Corredor de los Lagos” (Garcia; Valverde, 2006).

La expansión del turismo ha acarreado un "boom" inmobiliario en la localidad: Villa la

5. Con ello, no pretendemos establecer relaciones de causalidad entre la identidad étnica y el auge económico de Villa La Angostura, pero sí notar el contexto actual sobre el que se desenvuelve un grave conflicto de intereses por el acceso a la tierra desde distintos actores locales y extra locales.
Angostura se encuentra entre los primeros municipios en superficie y cantidad de permisos de construcciones nuevas, hecho por demás elocuente ya que su incidencia poblacional sobre el total de la provincia es ínfima (Provincia de Neuquén, 2004).

$\mathrm{Al}$ igual que lo que hemos registrado en otras localidades con presencia de población indígena la actividad turística, por un lado, crea una multiplicidad de conflictos y disputas por el acceso a los recursos. En este sentido, los pobladores señalan las dificultades para efectuar un aprovechamiento de este mercado a través de la venta de diferentes producciones:

Pero ahora no se puede vender casi nada porque hay mucha gente que viene de afuera y le dan la posibilidad más a ellos que a uno. Porque yo antes vendía hongos en escabeche, dulces caseros, todas esas cosas las fui a vender a la feria municipal.

Otro integrante de estas familias destaca:

Hay que pedir muchos permisos y si uno quiere hacer algo, como saben que no tengo, lo primero que hacen, me piden títulos...

Cabe señalar que en este contexto de ausencia de reconocimiento jurídico de las poblaciones indígenas por su territorio, las situaciones conflictivas se agudizan, ya que estas áreas resultan de sumo interés para diversos emprendimientos turísticos e inmobiliarios.

\section{El proceso de re-adscripción étnica en el contexto de explotación turística}

En este contexto de fuerte expansión turística, las familias mapuche de la zona parecen estar revirtiendo el histórico proceso de desadscripción étnica que hemos analizado precedentemente. Su aparición en la arena pública, 
disputando política y jurídicamente un status particular en términos de derechos indígenas, ha impugnado la construcción imaginaria de Villa la Angostura como una localidad "sin mapuche". En este punto nos centramos, por lo tanto, en la reafirmación identitaria y en la movilización étnica que vienen efectuando las familias Paichil-Antriao y Quintriqueo, con un creciente nivel de impacto mediático.

Los hombres y mujeres que reivindican su identidad mapuche son hijos o nietos de los pobladores originarios e "históricos" de la localidad. Esta población ocupa los estratos más empobrecidos de la escala social, padeciendo precarias condiciones laborales, elevados niveles de desempleo, etc. La inserción laboral de las mujeres se da en el servicio doméstico, mientras que los hombres se emplean en la construcción, o bien como chóferes, mecánicos, jardineros, ordenanzas, etc. También lo hacen en los puestos menos calificados vinculados al turismo (limpieza y mantenimiento en hoteles, restaurantes, confiterías, etc.). Otra opción laboral es la contratación por parte de organismos del Estado, también en tareas de poca jerarquía.

La primera de estas familias, Paichil Antriao, se ubica sobre la ladera del Cerro Belvedere, dentro del ejido municipal a $2 \mathrm{~km}$ del centro de Villa La Angostura (además del área que ocupa dentro del Parque). Está compuesta aproximadamente por 50 grupos familiares descendientes de las dos familias a las cuales les fuera asignado el lote 9 en el año 1902. Unos 30 residen en Villa la Angostura y los restantes en otras localidades. La extensión de las tierras en manos de los Paichil Antriao se ha reducido considerablemente, ya que actualmente, buena parte del antiguo lote "9" es un lujoso barrio residencial que alberga importantes construcciones, tanto hogareñas como turísticas.

El segundo caso corresponde a la familia Quintriqueo, asentada en Paso Coihue, a mitad de camino entre Bariloche y Villa la Angostura.
Sus pobladores se dedican principalmente a la ganadería de vacunos y huertas. También parte de los mismos trabajan en diversos empleos en las ciudades próximas, precisamente ante la imposibilidad de satisfacer sus necesidades a partir de las actividades prediales.

En los últimos cuatro años, en forma concomitante con el "boom" turístico de la región, ambos grupos de familias iniciaron una serie de reclamos, exigiendo su reconocimiento como población originaria con los mismos derechos jurídicos que la provincia otorga a otras agrupaciones de la provincia, lo que incluye la regularización territorial. Si bien la agrupación Paichil Antriao y Quintriqueo han sido reconocidas por el INAI (está tramitando su formalización jurídica), por la Administración de Parques Nacionales y por la Confederación Mapuche Neuquina (organización etnicista de la provincia); el gobierno provincial las desconoce, impidiendo que cuenten con el título comunitario de sus territorios ${ }^{6}$.

Entre abril y junio del 2003, la zona rural de Villa La Angostura fue escenario de un conflicto que comenzó cuando integrantes de la familia Quintriqueo fueron desalojados de los campos de Paso Coihue - que ocupan desde al menos mediados del siglo XIX-. El paraje es un sitio paradisíaco con vista al brazo Huemul del Lago Nahuel Huapi y una bahía con playa que lo transforma en un sitio ideal para un complejo turístico. Los pobladores reaccionaron rápidamente: el 25 de Mayo (10 días después de ser desalojados), unas 50 personas mapuche y no mapuche recuperaron pacíficamente la zona en litigio (Moyano, 2004). A los pocos días, un fallo judicial considerado inédito por

6. El lof Quintriqueo se encuentra lindero al ejido municipal, pero habita sobre territorio incuido en el Parque Nacional Nahuel Huapi. Por ello, la regularización de su situación como comunidad ancestral corresponde, parte, al Estado Nacional a través de la Administración Parques Nacionales. 
los beneficiados ordenó restituir el campo de 700 hectáreas de Paso Coihue a los Quintriqueo (Diario "La Mañana del Sur", 05/06/03). Con este hecho, Villa la Angostura pasaba a tener presencia mediática a raíz de los conflictos vinculados a su población originaria.

Desde entonces, los indígenas que permanecieron en el lugar recogieron la solidaridad de numerosas organizaciones y comunidades, a la vez que fueron experimentando un proceso de fortalecimiento de la identidad mapuche, acentuando la participación en organizaciones etnicistas y de pertenencia al territorio. Estas acciones se instalaron frente a la opinión pública, visibilizándose la presencia indígena en una localidad que ha negado sistemáticamente la existencia de pobladores originarios entre sus habitantes.

Una de las consecuencias del proceso protagonizado por estas familias indígenas se vería unos meses después, en diciembre del 2003, cuando se desató un conflicto que tuvo como protagonistas a los Paichil Antriao. En ese momento, en pleno "boom" turístico de la localidad, los pobladores iniciaron una "acampada" como respuesta a la tala de árboles en una zona del lote 9, sobre la ladera del Cerro Belvedere. El campamento tenía como finalidad remarcar la pertenencia al territorio mapuche y evitar las acciones de usurpación que se efectuaban con el fin de aprovechar turísticamente estos bellísimos y valiosos lugares. A través de estas acciones también se buscaba la restitución de los cientos de hectáreas que les fueron arrebatadas a través de las maniobras ya mencionadas, y la obtención del título comunitario del territorio.

El proceso de reafirmación de la pertenencia territorial y de los derechos en términos de adscripción étnica ha llevado a la judicialización del conflicto, con la permanente amenaza de desalojo de los pobladores y la situación de inestabilidad que esto implica. De hecho, el 21 de Abril del 2005 las fuerzas de seguridad desalojaron violentamente a estas familias a partir de la demanda presentada a la justicia por un particular. A los pocos días, un importante grupo mapuche retornó al lugar, reavivando el conflicto y su fuerte presencia periodística en la cotidianeidad de la localidad. Hasta el momento las familias continúan asentadas sobre el Cerro Belvedere y se mantiene un juicio de desalojo por privados que reclaman los costosos predios sobre los que están establecidos los mapuche.

Un factor para dar cuenta de la movilización indígena está dado, por las políticas que actualmente son contradictorias desplegadas desde los diferentes organismos del Estado (nacional, provincial y municipal). Es a partir de la compleja y dinámica relación que estas instituciones establecen con distintos interlocutores, producto de una disputa económica y política que en gran medida se retroalimenta esta movilización. Es por ello que las contradicciones dadas hacia adentro del Estado pueden actuar asignando un contexto que favorezca la movilización etnopolítica. Trinchero (2000) llama a esto "identidades políticamente estigmatizadas” (p. 289) que constituyen, de acuerdo a lo que retoma Vázquez:

(...) identidades estructuradas en los códigos de visibilización generados desde el poder político que en un momento dado gobierna el Estado y en general desde los partidos políticos que reconocen la "otredad" a través de dispositivos propios y susceptibles de enredar las identidades étnicas (Vazquez, 2004, p. 145).

En esto juegan un rol clave las contradicciones del mismo Estado y las luchas políticas hacia el interior de los sectores de poder que se disputan la hegemonía del mismo (Trinchero, 2000, Vazquez, 2004).

En el contexto local, el Estado provincial y municipal opera desconociendo el reclamo indígena, negando la categoría legal de "comunidad" a las familias en cuestión y promoviendo la venta de tierras y los juicios de desalojo. 
En cambio, el Estado nacional contribuye a la organización del "colectivo mapuche" de Villa La Angostura a través de su incorporación en el co-Manejo del Parque Nacional Nahuel Huapi, y a través del Instituto Nacional de Asuntos Indígenas en el asesoramiento y financiamiento de distintos proyectos vinculados a la reafirmación de la adscripción étnica y los derechos que esto trae aparejado. En este sentido, un funcionario del INAI declaraba a la prensa local:

(...) en el caso de comunidades asentadas ancestralmente en tierras privadas, lo que hay que hacer es ir a la justicia para que los jueces hagan una declaración de certeza. Que vale más: ¡la posesión tradicional de una comunidad indígena o un título frío donde no hay ocupación? (Moreda, 2005).

Es, entonces, en el marco de esta disputa política entre la provincia y la nación que se inserta la reivindicación étnica de los mapuche de Villa la Angostura.

Lo paradójico del proceso en curso es cómo los roles de las diversas instituciones y sus posicionamientos políticos se han invertido en los últimos años respecto de sus lineamientos históricos. Esto evidencia la trascendencia del rol del Estado en los procesos de conformación de las identidades, y tal como señalamos, en el abordaje teórico, la imposibilidad de separar el análisis de las mismas de estas configuraciones en su devenir histórico.

\section{El proceso de re-adscripción étnica: las estrategias de las organizaciones etno-políticas mapuches}

En este punto atenderemos a las estrategias etnopolíticas desplegadas por las familias Paichil Antriao y Quintriqueo. Una primera cuestión reside en la búsqueda del reconocimiento como mapuches que, con particular énfasis, encontramos en los pobladores de la localidad. Los pobladores remarcan su presencia "histórica” y su contribución al crecimiento de la villa. Como afirmaba una entrevistada:

Yo nací, me crié acá. Los documentos dicen Correntoso, nacida en Correntoso, así que es acá. Ese era el muelle viejo, donde mi bisabuelo, mi abuelo, mi padre, de ahí salían ¡mirá si no es histórico! De ahí salían para hacer, mi bisabuelo, el amojonamiento, la limitación para la medición. De ahí salían y eran los únicos que tenían bote, los Antriao.

Asimismo, otra pobladora señalaba:

Yo trabajé en la escuela cuando estaba en la Villa. Conocí la primera maestra cuando recién abrieron la escuela ahí en la Villa, y empezaron a ir los chicos. Porque acá todavía no conocían colegios los chicos, se abrió después, vinieron después, cuando ya estaba hecho medio pueblo.

Dentro del proceso de reconocimiento de sus derechos ancestrales que afirman estas familias, se evidencian los aspectos de la cultura mapuche:

Yo se interpretar toda la lengua. Y sé hacer todo lo que hacíamos los Mapuches en la tierra porque mi padre me lo enseño.

Es por esto que en las expresiones vertidas por los entrevistados se observa como, dentro el proceso de movilización reciente, se busca el afianzamiento identitario que fueron perdiendo a lo largo del Siglo XX:

En 2 años se logró la reorganización en que ya varias familias se van reconociendo mapuches. Porque eso es lo más difícil. O sea que se reconozcan mapuches. Que la cultura que les impusieron nada que ver con la mapuche. Como decir 
que el ser indio es una mala palabra, y no es así. Tenemos que sentirnos orgullosos de pertenecer a una raza que fuimos los primeros ¿̨no?.

Otras expresiones se refieren a:

Con mi hermana vamos a la ceremonia, al ańo nuevo mapuche (...). Yo lo que tengo muchas ganas de que algún día podamos hacer las ceremonias en nuestro lugar.

Por otro lado, las estrategias desplegadas por las familias indígenas apuntan a obtener un destacado impacto mediático. Por esto es que las protestas se centran en las preciadas áreas del Cerro Belvedere al que acceden turistas para visitar el "mirador" Inacayal. En el lugar han buscado generar una fuerte repercusión, remarcando que es "territorio mapuche" mediante una bandera en el lugar, lo que despierta la atención a los visitantes. Otra de las estrategias desplegadas por las familias mapuche es la búsqueda de beneficios por la práctica de esta actividad, ya que además los pobladores observan las potencialidades que asigna su identidad étnica. De hecho, con las limitaciones propias de la situación jurídica en que se encuentran, los mapuche efectúan diversas actividades para este mercado (un estacionamiento para los turistas que van a conocer el Cerro Belvedere, cabalgatas, alquiler de canoas en la costa del Lago Correntoso y un embarcadero de lanchas y excursiones de pesca sobre el Lago Nahuel Huapi). En estos pequeños emprendimientos de carácter netamente familiar no existe ningún tipo de financiamiento estatal ni promoción institucional para las actividades.

Pero el acceso a los beneficios de esta actividad no se restringe a la obtención de un ingreso, ya que además, el contacto con los turistas les permite a las poblaciones originarias obtener la solidaridad y divulgar su problemática.
Como mencionó una entrevistada en relación al contacto con el turismo en el Belvedere:

El reconocimiento a las comunidades del turismo es positivo. Aparte que la gente quiere saber cómo fue, cómo es. Porque se ocultó tantos ańos, y como ahora se esta escuchando, se siente más el ruido mapuche.

Un testimonio similar recogemos en relación al conflicto del Lof Quintriqueo de principios del 2003:

¿Sabe lo que nos decían los turistas?; sigan luchando, no se dejen quitar porque acá están mal acostumbrados. A la gente pobre la corren, a la gente pobre no la dejan tranquila, así que, sigan luchando entre todos, eso nos decían los turistas.

Esta participación en el mercado turístico busca modificar los discursos hegemónicos que deslegitiman la presencia indígena en la zona.

Como última estrategia, debemos mencionar la articulación que establecen con una diversidad de sectores sociales. En el contexto de Villa la Angostura, la menor trascendencia del estado y de diversos sectores sociales (movimientos sociales, ONG's, etc.) que en otras localidades de Neuquén hace que haya una menor presencia de sectores sociales con quienes establecer alianzas. No obstante, se da una importante solidaridad de agrupaciones indígenas y sectores sociales de otras localidades. Como señaló uno de los Antriao entrevistados:

Vamos a todas las reuniones que se puede ir, en Bariloche...a la de Junín, a San Martín... Yo a la de Chubut fui. Fuimos a la reunión esa en Vuelta del Río...porque allá se juntan de todos lados...

7. Se refiere al Parlamento Mapuche de la provincia de Chubut (estado provincial localizado al sur de Neuquén) efectuado en el paraje "Vuelta del Río". 
I 24 Sebastián Valverde e Analía García

Paradójicamente el aislamiento del resto de la provincia y la influencia de Bariloche, que, como vimos, ha contribuido en el proceso histórico a la des-adscripción identitaria, en la actualidad constituye un factor que refuerza el reclamo de las familias mapuche.

\section{Consideraciones finales}

A partir de lo analizado a lo largo del presente artículo observamos como el proceso histórico ocurrido en el Departamento "Los Lagos" impuso relaciones sociales particulares en el acceso a la tierra, que garantizaron la inserción subordinada de los pobladores de origen mapuche en el sistema productivo. No obstante, las especificidades locales no definieron a la adscripción étnica como forma de legitimación simbólica y económica. De allí que las políticas desplegadas por las instituciones locales han llevado a la des-adscripción étnica de estas familias a lo largo del siglo XX. Siguiendo a Bartolomé comprobamos como:

(...) la constante inferiorización material y simbólica de las sociedades nativas ha conducido al desarrollo de procesos tipificables como etnocidios (Bartolomé, 1997, pp. 72 - 73)

ya que el proceso de des-adscripción sufrido a lo largo del siglo XX se ha visto acompañado de estrategias como la apropiación de tierras por parte de otros sectores de la población local.

Esto resulta de colocar a una sociedad en situaciones físicas e ideológicas que imposibilitan o dificultan extraordinariamente su reproducción social e identitaria. Dichos procesos comienzan por el abandono de rasgos culturales propios, continúan con el reemplazo lingüístico y concluyen con la renuncia a la filiación indígena: el progresivo abandono del mundo cultural concluye en una descaracterización étnica. Pero el abandono de la cultura no suponen necesariamente la renuncia de la identidad, aunque es frecuente que se den asociadas (Bartolomé, 1997, p. 72-73).

Por ello, en lugar de plantear la identidad étnica como una enumeración de rasgos culturales, los procesos de adscripción y des-adscripción étnica para el caso aquí analizado, fueron contemplados a partir de la compleja y dinámica relación que los actores establecen con distintos interlocutores y como producto de una disputa económica y política en la arena pública. En este sentido, resultan paradójicos los cambios operados en las conformaciones del Estado en sus diferentes niveles para el caso de Villa la Angostura.

Al mismo tiempo que la provincia de $\mathrm{Neu}$ quén reconocía comunidades en su territorio durante los años 1960, Parques Nacionales desconocía la adscripción étnica de la población asentada en el parque, contribuyendo de esta manera a su "invisibilización". El aislamiento en el que se enmarca el proceso histórico de conformación de la soberanía nacional en los territorios patagónicos, y su relativo fracaso en términos de conformación de colonias agrícolas en pos de la constitución de grandes latifundios, constituyó un factor determinante para el proceso que viven en la actualidad las familias mapuche de Villa la Angostura.

Nuestra hipótesis de trabajo ha sido que los procesos de adscripción y des-adscripción étnica se encuentran condicionados por la institucionalidad política y por las condiciones económicas de cada coyuntura, que viabilizan u obstaculizan reclamos de esta índole. En este sentido, reconocemos distintas posiciones a nivel nacional y provincial. Consideramos que estas diferencias se deben a las contradicciones dadas hacia adentro del Estado como consecuencia de su posicionamiento relativo en términos materiales y 
simbólicos dado por el federalismo político y jurídico.

En la actualidad, esta situación se ha invertido. Mientras la provincia niega el reconocimiento comunitario, la Nación opera sobre diversas estrategias que fomentan la adscripción étnica. En este sentido, entendemos que el proceso de movilización social que lleva adelante estas familias permite "desnaturalizar" la presencia de las comunidades indígenas ya que, contrariamente a lo que acepciones del sentido común y de determinados abordajes antropológicos, dista de ser un proceso "dado" sino la resultante de un proceso histórico específico.

Interethnical relations, identity construction processes and Mapuche ethnic and political strategies at the Los Lagos Department, Neuquén, Argentina

abstract This research aims at analizing the indentity ethnic construction process within families with Mapuche ancestors in Villa la Angostura (Los Lagos Department) in the province of Neuquén in relation to the policies carried out by the $\mathrm{Na}$ tional and Provincial States. For this, we propose as a working hypothesis different national scenarios from which during the 20th century, the "ethnic" identity caused a prejudice to the situation of these domestic groups in terms of their right to the land.

For this we analyze the role played by the state institutions in charge of regulating this right. Later we wonder about the social movilization process which arose in 2003 focused on the economic context which envolves the city. In that field we study the different state policies with an aim to promoting this kind of claim and we account for their incidence when visualizing the protest and revaluation of the Mapuche identity.

keywords Indigenous. State. Identity.

\section{Referencias bibliográficas}

ADMINISTRACION parques nacionales. Ficha individual de pobladores, año 1934. Parque Nacional Nahuel Huapi, 1934.

BARTH, Fredrik. "Introdución". In: BARTH, Frederik (org.). Los grupos étnicos y sus fronteras. Fondo de Cultura Económica. México, 1976. p. 9-49.

BARTOLOME, Miguel Alberto. Gente de costumbre y gente de razón: las identidades étnicas en México. Siglo XXI: México, 1997. 222p.

BECHIS, Martha. "Instrumentos para el estudio de las relaciones interétnicas en el periodo formativo y consolidación de los estados nacionales". In: HIDALGO, Cecilia y TAMAGNO, Liliana (comp.) Etnicidad e Identidad. Centro Editor de América Latina: Buenos Aires, 1992, p. 82-108.

BELLI, Elena; SLAVUTSKY, Ricardo. "Procesos de reconfiguración étnica y movimientos sociales en el NOA". In: Estudios sociales del NOA. no. 6. Instituto Interdisciplinario Tilcara. Facultad de Filosofía y Letras, UBA, 2003, p. 5-35.

CARDOSO DE OLIVEIRA, Roberto. Etnicidad y estructura social. CIESAS, Colección Miguel Othón de Mendizábal: México, 1992. 158p.

DE MENDIETA, Yayo. Una Aldea de Montaña. Villa la Angostura y su historia en la Patagonia. Bavaria: S. C. de Bariloche, 2002. 341p.

DIARIO La Mañana del Sur 05/06/03.

DIAZ POLANCO, Héctor. Etnia y Nación en América Latina. Consejo Nacional para la Cultura y las Artes: México, 1995. 408p.

FALASCHI, Carlos. La Confederación Indígena Neuquina. Serie La Tierra Indigena Americana, vol. 4. I.R.E.P.S. - A.P.D.H. Neuquén, Argentina, 1994. 27p.

FAVARO, Orietta. "Territorio y Estado nacional: Estado provincial y sistema político (1955 - 1976)”. In: BANDIERI, Susana; FAVARO, Orietta y MORINELLI, Marta (comp.), Historia de Neuquén. Colección Historia de nuestras provincias. Plus Ultra: Buenos Aires, 1993. p. 315-331.

GARCIA, Analía; VALVERDE, Sebastián. "Adscripción y desadscripción étnica como estrategia de disputa. El caso de los Paichil Antriao y los Quintriqueo de Villa la Angostura”. In: 8vo Congreso Argentino de Antropología Social, Universidad Nacional de Salta, Ciudad de Salta, del 19 al 22 de septiembre de 2006. 20p.

HIDALGO, Cecilia, Prólogo. In: HIDALGO, Cecilia y TAMAGNO, Liliana (comp.). Etnicidad e Identidad. Centro Editor de América Latina: Buenos Aires, 1992. p. 7-12. 
I 26 Sebastián Valverde e Analía García

INDEC. Censo Nacional de Población, Hogares y Viviendas 2001. Buenos Aires: Argentina, 2001.

INDEC. Encuesta Complementaria de Pueblos Indigenas. Buenos Aires: Argentina, 2006.

MENDEZ, Laura. "Mi pasado me condena. Chilenos e indígenas en el Nahuel Huapi 1880-1935”. In: VI Congreso de Historia Politica y Social de la Patagonia Argentino - Chilena. 13, 14 y 15 de Octubre de 2005. Universidad Nacional de la Patagonia "San Juan Bosco".

MOREDA, Nadina. Recuperación del territorio de la comunidad Paichil Antriao. In: Foja 0. Nadina Moreda y Martín Zubieta (eds.), San Carlos de Bariloche, Argentina, No. 3, Mayo 2005.

MOYANO, Adrián, Puelmapu. El regreso al territorio. In: AZkintuWE Periódico Mapuche, No. 4, Marzo de 2004, IX Región, Chile, 2004. p. 5-7.

MUNICIPALIDAD de Villa la Angostura. Secretaria de Turismo y Producción. Guía de inversores. 2006. http://www.villalaangostura.gov.ar/inversores

PROVINCIA de Neuquén. Estadísticas de Permisos de Edificación - Resultados Definitivos Año 2004. 63p.

RADOVICH, Juan Carlos. "Política Indígena y Movimientos Etnicos: el caso Mapuche”. In: Cuadernos de Antropología, vol. 4, Universidad Nacional de Luján, 1992, p. 47-65.

SUBSECRETARÍA de turismo - provincia de Neuquén. Guía para inversores Villa la Angostura. 2006. 59p.

TRINCHERO, Hugo. Los Dominios del Demonio. EUDEBA, Buenos Aires, 2000. 383p.

VALLMITJANA, Roberto. "Aborígenes en la Colonia Agrícola Nahuel Huapi”. In: Jornadas de Historia Rio- negrina, Bariloche, Universidad FASTA, Octubre de 1999. 20p.

VALLMITJANA, Roberto. "A cien años de la Colonia Agrícola Nahuel Huapi 1902-2002”. In: Archivo Histórico Regional. S. C. de Bariloche, Argentina, 2002. 62p.

VÁZQUEZ, Héctor, Antropología Emancipadora, Derechos Humanos y Pluriculturalidad. Homo Sapiens: Rosario, Argentina, 2004. 166p.

\section{Agradecimentos}

El presente trabajo ha sido financiado por el Proyecto de la Agencia Nacional de Promoción Científica y Tecnológica: "Problemática artesanal indigena. Procesos productivos y de comercialización: un análisis comparativo de grupos Mapuche, Chané y Wichi" y el Proyecto UBACyT "Explotaciones turisticas y comunidades mapuches: conflicto interétnico y prácticas de reproducción social en Norpatagonia". Facultad de Filosofía y Letras - UBA. Agradecemos a la Biblioteca Popular "Osvaldo Bayer" de Villa la Angostura por el apoyo brindado en la zona que hizo posible la realización del presente trabajo.

\section{autor Sebastián Valverde}

Investigador do CONICET. Instituto de Ciências Antropológicas/UBA

Doutor em Ciências Antropológicas

\section{autor Analía García}

Doutoranda do CONICET. Instituto de Ciências Antropológicas/UBA

Recebido em 31/03/2007

Aceito para publicação em 28/11/2007 